\title{
(W) Self-monitoring of oral anticoagulation: systematic review and meta-analysis of individual patient data
}

\author{
Carl Heneghan, Alison Ward, Rafael Perera, Clare Bankhead, Alice Fuller, Richard Stevens, Kairen Bradford, Sally Tyndel, Pablo Alonso-Coello, \\ Jack Ansell, Rebecca Beyth, Artur Bernardo, Thomas Decker Christensen, Manon Cromheecke, Robert G Edson, David Fitzmaurice, \\ Alain P A Gadisseur, Josep M Garcia-Alamino, Chris Gardiner, Michael Hasenkam, Alan Jacobson, Scott Kaatz, Farhad Kamali, \\ Tayyaba Irfan Khan, Eve Knight, Heinrich Körtke, Marcel Levi, David Bruce Matchar, Bárbara Menéndez-Jándula, Ivo Rakovac, Christian Schaefer, \\ Andrea Siebenhofer, Juan Carlos Souto, Rubina Sunderji, Kenneth Gin, Karen Shalansky, Heinz Völler, Otto Wagner, Armin Zittermann, and \\ The Self-Monitoring Trialist Collaboration
}

Lancet 2012; 379: 322-34

Published Online December 1, 2011

DOI:10.1016/S01406736(11)61294-4

This online publication has been corrected. The corrected version first appeared at thelancet.com on March 23 , 2012

See Comment page 292 Oxford University, Department of Primary Care Health Sciences, Oxford, UK (C Heneghan DPhil, A Ward PhD, R Perera DPhil, C Bankhead DPhil,

A Fuller BSc, R Stevens PhD,

K Bradford MA, STyndel PhD, J M Garcia-Alamino RN); Iberoamerican Cochrane Centre, Clinical Epidemiology and Public Health Department Institute of Biomedical Research [IIB Sant Pau], Barcelona, Spain (P Alonso-Coello PhD); Department of Medicine, Lenox Hill Hospital, New York, USA (Prof J Ansell MD); New York University School of Medicine (J Ansell); Division of Internal Medicine, University of Florida, FL, USA (R Beyth MD); North FL/South Georgia Veterans Health System, FL, USA (R Beyth); Klinik Gais AG, Gais,

Switzerland (A Bernardo MD); Department of Cardiothoracic and Vascular Surgery (T D Christensen DMSc, Prof J M Hasenkam DMSc), Institute of Clinical Medicine (T D Christensen), Aarhus University Hospital, Aarhus, Denmark; Department of Cardiopulmonary Surgery, Academic Medical Centre, University of Amsterdam, Netherlands

(M E Cromheecke PhD, M Levi PhD); VA Cooperative Studies Program Coordinating

Center, Palo Alto, CA, USA (R G Edson MA); Department of

\section{Summary}

Background Uptake of self-testing and self-management of oral anticoagulation has remained inconsistent, despite good evidence of their effectiveness. To clarify the value of self-monitoring of oral anticoagulation, we did a metaanalysis of individual patient data addressing several important gaps in the evidence, including an estimate of the effect on time to death, first major haemorrhage, and thromboembolism.

Methods We searched Ovid versions of Embase (1980-2009) and Medline (1966-2009), limiting searches to randomised trials with a maximally sensitive strategy. We approached all authors of included trials and requested individual patient data: primary outcomes were time to death, first major haemorrhage, and first thromboembolic event. We did prespecified subgroup analyses according to age, type of control-group care (anticoagulation-clinic care vs primary care), self-testing alone versus self-management, and sex. We analysed patients with mechanical heart valves or atrial fibrillation separately. We used a random-effect model method to calculate pooled hazard ratios and did tests for interaction and heterogeneity, and calculated a time-specific number needed to treat.

Findings Of 1357 abstracts, we included 11 trials with data for 6417 participants and 12800 person-years of follow-up. We reported a significant reduction in thromboembolic events in the self-monitoring group (hazard ratio $0.51 ; 95 \% \mathrm{CI}$ $0 \cdot 31-0 \cdot 85)$ but not for major haemorrhagic events $(0 \cdot 88,0 \cdot 74-1.06)$ or death $(0 \cdot 82,0 \cdot 62-1.09)$. Participants younger than 55 years showed a striking reduction in thrombotic events (hazard ratio $0 \cdot 33,95 \%$ CI $0 \cdot 17-0 \cdot 66$ ), as did participants with mechanical heart valve $(0.52,0 \cdot 35-0 \cdot 77)$. Analysis of major outcomes in the very elderly (age $\geq 85$ years, $n=99$ ) showed no significant adverse effects of the intervention for all outcomes.

Interpretation Our analysis showed that self-monitoring and self-management of oral anticoagulation is a safe option for suitable patients of all ages. Patients should also be offered the option to self-manage their disease with suitable health-care support as back-up.

Funding UK National Institute for Health Research (NIHR) Technology Assessment Programme, UK NIHR National School for Primary Care Research.

\section{Introduction}

Oral anticoagulation with vitamin $\mathrm{K}$ antagonists substantially reduces the incidence of thromboembolic events..$^{1+4}$ Although the number of patients receiving oral anticoagulants has consistently increased, uptake is limited by requirements to maintain the international normalised ratio (INR) within a narrow target range, which includes frequent testing and appropriate dose adjustments. Benefits shown in clinical trials might not translate into routine practice: namely the risk of major bleeding could be high in specific populations of patients, especially in the elderly. ${ }^{2}$

Introduction of reliable and analytically accurate pointof-care devices allows self-testing by the patient in the home setting. ${ }^{12}$ Patients can have their test result managed by their health-care provider (self-testing) or they can interpret their INR result, and adjust their own dose of anticoagulant accordingly (self-management).
Previous systematic reviews ${ }^{46}$ showed that selfmonitoring is a safe intervention, which gives rise to significant reduction in thromboembolic events, while reducing the risk of death. Additionally, patients spend more time in the therapeutic range of INR than they would without self-monitoring. However, previous conclusions were limited by methodological problems and inadequate reporting of important outcome data over time..$^{46}$ Also important subgroup analyses, stratified by age and indication for anticoagulation therapy, have not been possible.

Uptake of self-testing and self-management has remained inconsistent in and between countries, despite good evidence of their effectiveness and guidelines encouraging patients to discuss this option with clinical staff. ${ }^{1,7}$ To clarify further the value of self-monitoring of oral anticoagulation we did a meta-analysis of individual patient data, which updated our previous systematic 
reviews and enabled more detailed analysis than previously. Specifically, we aimed to address several important gaps in the evidence, including obtaining an estimate of the effect of self-monitoring on time to death, first major haemorrhage, and first thromboembolic event. We also aimed to investigate effects in important subgroups such as the elderly and those with specific disease indications for anticoagulation such as atrial fibrillation or mechanical heart valve.

\section{Methods}

\section{Search strategy and study selection}

The protocol methods have been previously published. ${ }^{\text {We }}$ used the same search strategy as for previous reviews. ${ }^{46}$ We searched Ovid versions of Embase (1980-2009) and Medline (1966-2009), limiting searches to randomised trials with a maximally sensitive strategy. ${ }^{10}$ A list of search terms is shown in webappendix pp 1-3. We modified these searches for the Cochrane Central Register of Controlled Trials, the Cochrane Library, issue 2, 2009, and Cinahl (1982-2009). We also searched for trials that are still underway or unpublished (eg, UK National Research Register and Trials Central), and handsearched reference lists of retrieved papers.

\section{Trial eligibility and quality assessment}

We included randomised trials that compared the effects of self-monitoring (self-testing) or self-management (self-testing and self-dosage) of anticoagulation with control and dosage by personal physician, anticoagulation management clinics, or managed services, or reported the clinical outcomes of thromboembolic events and major bleeding episodes. We included studies of adults on anticoagulant therapy irrespective of the indication for treatment, with no language restrictions.

As in our previous systematic review, ${ }^{5}$ we assessed the quality of studies by the presence of randomisation, allocation concealment, masked outcome assessments, intention-to-treat analysis, and attrition rates. Two reviewers ( $\mathrm{CH}$ and $\mathrm{AW}$ ) independently assessed the articles for inclusion, and disagreements were resolved by discussion.

\section{Data extraction}

We approached all authors whose trials met the inclusion criteria and requested the following data for individual patients: date of randomisation, age, indication for treatment, type of care, demographic and psychosocial characteristics at randomisation including quality-of-life measures, treatment allocation, time to death, time to first major haemorrhage, time to first thromboembolic event, and INR measurements.

\section{Data validation}

We kept original data on a secure server with a back-up copy according to a prespecified data-security-agreement policy. Two researchers (CB and AF) cross-checked trial details, summary measures, and major outcomes were cross-checked with prespecified outcome definitions against published articles. Any inconsistencies were discussed with the original trialist and corrections were made when appropriate. Requirements for authorship were those of the International Committee of Medical Journal Editors and a representative of each trial was invited to an investigators' meeting before publication to discuss analysis and results.

\section{Statistical analysis}

Primary outcomes were time to death, first major haemorrhage, and first thromboembolic events. Major haemorrhages included: 1) bleeding that was fatal, 2) symptomatic bleeding in a critical area or organ such as intracranial, intraspinal, intraocular, retroperitoneal, intra-articular or pericardial, or intramuscular with compartment syndrome; and 3) bleeding causing a fall in haemoglobin concentrations of $20 \mathrm{~g} / \mathrm{L}(1.24 \mathrm{mmol} / \mathrm{L})$ or more, or leading to transfusion of two units of packed red-blood cells. Thromboembolic events were stroke, arterial embolism, symptomatic deep-vein thrombosis, or pulmonary embolism. ${ }^{11}$

One secondary outcome was time in therapeutic range. For individual data, time-to-event outcomes were summarised as log (hazard ratio), and time in range as mean (SD). We used the survival-curve and hazard-ratio programme SCHARP (version 4) for meta-analysis of individual patient data. SCHARP is an SAS application for meta-analysis of individual patient data with a point and-click interface that produces publication-quality graphs and appropriate summary statistics for time-toevent data. ${ }^{12}$

We used SPSS (version 17) for analysis of baseline characteristics. We did prespecified subgroup analyses for the primary outcomes with the following age bands $(<55$ $55-64,65-74$, and $\geq 75$ years), the type of control-group care, type of self-monitoring, and sex. We also analysed patients who had mechanical heart valves, atrial fibrillation, and other indications separately, stratifying them by age ( $<65$ years and $\geq 65$ years).

Because the components of the interventions differ somewhat (eg, in terms of their training and education) and in assuming a different underlying effect for each trial intervention, a random effects model was used to calculate pooled hazard ratios. Random effects generally lead to wider CIs than the fixed effects; however, when no heterogeneity is present the results of the fixed and random effects are equivalent. Time-to-event outcomes were analysed with hazard ratios, which take into account the number and timing of events, and the time until last follow-up for each patient not experiencing an event. We used a two-step process for meta-analysis: a hazard ratio was estimated for each trial and then hazard ratios were pooled in a meta-analysis. The log-rank observed-minus-expected statistic and its variance were
Primary Health Care and General Practice, Medical School, University of Birmingham, Birmingham, UK (Prof D Fitzmaurice MD); Department of Haemotology, Antwerp University Hospital, Edegem, Belgium (A P A Gadisseur PhD); Nuffield Department of Obstetrics and Gynaecology, University of Oxford, John Radcliffe Hospital, Headley Way, Headington, Oxford, UK (C Gardiner PhD), Research and Development Service, Jerry L Pettis VA Medical Centre and Department of Internal Medicine, Loma Linda University, CA, USA (A Jacobson MD); Department of Internal Medicine, Henry Ford Hospital, Detroit, USA (S Kaatz DO); Institute of Cellular Medicine, Newcastle University, Newcastle upon Tyne, UK (Prof F Kamali PhD, TIrfan Khan PhD); Anticoagulation Europe, Kent UK (E Knight DipHPsych); Institute of Applied Telemedicine, Heart and Diabetes Centre North Rhine-Westphalia, Bad Oeynhausen, Germany (H Körtke PhD); Duke Center of Clinical Health Policy Research, Durham, NC, USA (Prof D Matchar MD) Department of Internal Medicine (General Internal Medicine), Duke University Medical Center, Durham, NC USA (D Matchar); Program in Health Services and Systems Research, Duke-NUS Graduate Medical School, Singapore (D Matchar); Unitat d'Hemostàsia i Trombosi, Hospital de la Santa Creu i Sant Pau, Barcelona, Spain (B Menéndez-Jándula MD, J ( Souto PhD);

Joanneum Research Forschungsgesellschaft $\mathrm{mbH}$, Institute for Biomedicine and Health Sciences, Graz, Austria (I Rakovac PhD); International Self-Monitoring Association of Oral Anticoagulation Patients [ISMAAP], Geneva, Switzerland (C Schaefer); Institute for General Practice, Goethe University, Frankfurt, Germany (Prof A Siebenhofer MD); Faculty of Pharmaceutical Sciences

(Prof R Sunderji PharmD, Prof K Shalansky PharmD), Faculty of Medicine (Prof K Gin FRCPC), University 
of British Columbia, Vancouver, BC, Canada; Vancouver General Hospital, Vancouver, Canada (R Sunderji, K Shalansky, K Gin); Center of Rehabilitation Research, Potsdam University, Potsdam, Germany (Prof H Völler MD); and Department of Thoracic and Cardiovascular Surgery (O Wagner MSc,

Prof A Zittermann PhD), Heart and Diabetes Centre North Rhine-Westphalia (O Wagner, A Zittermann), Ruhr Universität Bochum, Bad Oeynhausen, Germany Correspondence to: Dr Carl Heneghan, Oxford University, Department of Primary Care Health Sciences, 23-38 Hythe Bridge St, Oxford, OX12ET, UK carl.heneghan@phc.ox.ac.uk See Online for webappendix

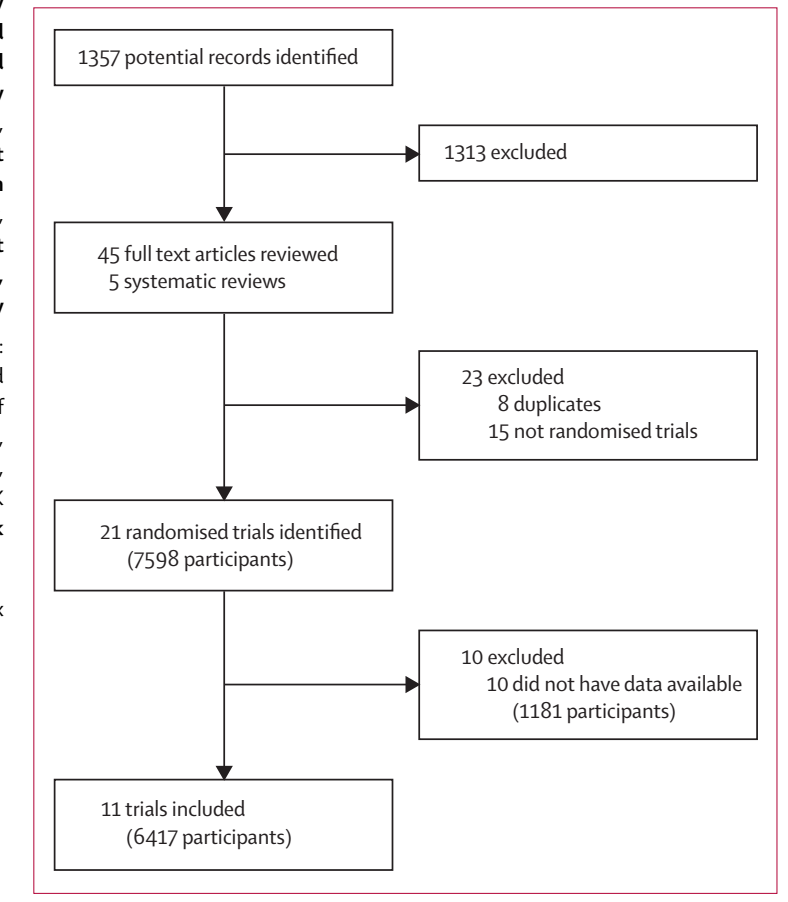

Figure 1: Flow chart of studies

calculated for each trial..$^{13}$ We examined heterogeneity with the $I^{2}$ statistics. ${ }^{14,15}$ We also did tests for interaction between subgroups of patients, partitioning the total heterogeneity across all trials into within-group and between-group heterogeneity (the test for interaction). We calculated a time-specific number needed to treat at various timepoints with the method outlined by Altman and Andersen, ${ }^{16}$

Number needed to treat $=\frac{1}{\left(\mathrm{Sc}[\mathrm{t}]^{\mathrm{h}}-\mathrm{Sc}[\mathrm{t}]\right)}$

where at a specified timepoint $(t)$, the survival probability in the control group is $\mathrm{Sc}(\mathrm{t})$, then the survival probability in the active group is $\mathrm{Sc}(\mathrm{t})^{\mathrm{h}}$, where $\mathrm{h}$ is the hazard ratio comparing the treatment groups. The number needed to treat represents the number of patients treated in the intervention group for one less primary outcome event over the time stipulated. For subgroups, we calculated the average effect over 5 years based on the control event rate. All analyses were on an intention to treat basis. We deviated from our original protocol in that we did not present data on psychological factors, which we hope to report elsewhere.

Sufficient data from eight trials ${ }^{17-24}$ were available for us to calculate the mean time in therapeutic range at timepoints of 7 days, 30 days, 90 days, 6 months, and 1 year by the method of linear interpolation set out by Rosendaal and colleagues. ${ }^{25}$ We assessed publication bias by constructing a funnel plot of precision (SE of the log hazard ratio) against hazard ratio for the endpoints of major haemorrhage and thromboembolic events, ${ }^{6}$ and did Begg's and Egger's tests.

\begin{tabular}{|c|c|c|c|c|c|c|c|c|c|c|c|c|}
\hline & Country & $\begin{array}{l}\text { Dates of } \\
\text { recruitment }\end{array}$ & $\begin{array}{l}\text { Year of } \\
\text { publication } \\
\text { of primary } \\
\text { results }\end{array}$ & $\begin{array}{l}\text { Study } \\
\text { duration } \\
\text { (months) }\end{array}$ & $\begin{array}{l}\text { Age range, } \\
\text { years (mean) }\end{array}$ & $\begin{array}{l}\text { Total } \\
\text { number of } \\
\text { patients }\end{array}$ & Female & $\begin{array}{l}\text { Atrial } \\
\text { fibrillation }\end{array}$ & $\begin{array}{l}\text { Mechanical } \\
\text { valve }\end{array}$ & Other & $\begin{array}{l}\text { Self } \\
\text { manage- } \\
\text { ment }\end{array}$ & $\begin{array}{l}\text { Type of control } \\
\text { group care }\end{array}$ \\
\hline Beyth et al ${ }^{36 *}$ & USA & 1992-95 & 2000 & 6 & $65-94(74 \cdot 7)$ & $325(5 \%)$ & $184(57 \%)$ & $54(17 \%)$ & $36(11 \%)$ & $235(72 \%)$ & No & Primary Care \\
\hline $\begin{array}{l}\text { Cromheecke } \\
\text { et } \mathrm{al}^{17} \dagger\end{array}$ & Holland & 1998 & 2000 & 3 & $22-71(42 \cdot 3)$ & $49(1 \%)$ & $21(43 \%)$ & $11(22 \%)$ & $23(47 \%)$ & $15(31 \%)$ & Yes & $\begin{array}{l}\text { Anticoagulation } \\
\text { clinic }\end{array}$ \\
\hline Koertke et al ${ }^{18} \dagger$ & Germany & 1994-97 & 2001 & 24 & $17-77(59 \cdot 7)$ & 930 (14\%) & $293(32 \%)$ &.. & $930(100 \%)$ & .. & Yes & Primary care \\
\hline Sunderji et $a^{37} \neq$ & Canada & 1998-2002 & 2004 & 20 & $20-85(60 \cdot 0)$ & $139(2 \%)$ & $41(29 \%)$ & $47(34 \%)$ & $82(59 \%)$ & $10(7 \%)$ & Yes & Primary care \\
\hline $\begin{array}{l}\text { Menéndez- } \\
\text { Jándula et } \mathrm{al}^{19} \dagger\end{array}$ & Spain & 2001-02 & 2005 & 12 & $19-90(63.5)$ & 737 (11\%) & $347(47 \%)$ & $296(40 \%)$ & $285(39 \%)$ & $154(21 \%) \S$ & Yes & $\begin{array}{l}\text { Anticoagulation } \\
\text { clinic }\end{array}$ \\
\hline Völler et al ${ }^{38} \dagger$ & Germany & 1999-2001 & 2005 & 19 ा & $36-85(64 \cdot 4)$ & $202(3 \%)$ & $53(26 \%)$ & $202(100 \%)$ & .. & .. & Yes & Primary care \\
\hline $\begin{array}{l}\text { Fitzmaurice } \\
\text { et } \mathrm{a}^{20} \dagger\end{array}$ & UK & 2001-02 & 2005 & 12 & $18-87(65 \cdot 1)$ & $617(10 \%)$ & $217(35 \%)$ & $343(56 \%)$ & $97(16 \%)$ & $177(29 \%)$ & Yes & Both \\
\hline $\begin{array}{l}\text { Christensen } \\
\text { et } \mathrm{al}^{21+}\end{array}$ & Denmark & 2002-03 & 2006 & 6 & $21-78(50 \cdot 7)$ & $100(2 \%)$ & $33(33 \%)$ & $24(24 \%)$ & $35(35 \%)$ & $41(41 \%)$ & Yes & Both \\
\hline $\begin{array}{l}\text { Siebenhofer } \\
\text { et } \mathrm{a}^{23+}\end{array}$ & Austria & $2002-05$ & 2007 & 36 & $60-89(68.8)$ & $195(3 \%)$ & $81(42 \%)$ & $89(46 \%)$ & $32(16 \%)$ & $74(38 \%)$ & Yes & Both \\
\hline Matchar et $\mathrm{al}^{22} \neq$ & USA & $2003-06$ & 2010 & 36 & $23-90(67 \cdot 0)$ & $2922(46 \%)$ & $51(2 \%)$ & $2236(77 \%) \|$ & $684(23 \%)$ & $2(<1 \%)$ & No & $\begin{array}{l}\text { Anticoagulation } \\
\text { clinic }\end{array}$ \\
\hline Kaatz et $\mathrm{al}^{24 \dagger}$ & USA & 1998-99 & 2001 & 12 & $30-87(64 \cdot 1)$ & $201(3 \%)$ & $84(42 \%)$ & $86(43 \%)$ & 39 (19\%) & $76(38 \%)$ & No & $\begin{array}{l}\text { Anticoagulation } \\
\text { clinic }\end{array}$ \\
\hline Totals & .. & $1992-2006$ & 2000-10 &.. & $17-94(65 \cdot 0)$ & 6417 & $1405(22 \%)$ & $3388(53 \%)$ & $2243(35 \cdot 0 \%)$ & $784(12 \%)$ &.. &.$\cdot$ \\
\hline
\end{tabular}




\section{Role of the funding source}

The sponsor of the study had no role in study design, data collection, data analysis, data interpretation, or writing of the report. The corresponding author had full access to all the data in the study and had final responsibility for the decision to submit for publication.

\section{Results}

Of 1357 abstracts, we identified 21 trials (20 published, one unpublished) that met the eligibility criteria (figure 1). We were unable to obtain adequate data from ten trials. ${ }^{26-35}$ These trials were small, ranging from 50-320 participants (total 1181 participants). Of 21 original trials, including 7598 participants, we present results for 6417 (84\%) participants.

Table 1 shows 11 included trials: three in the USA, ${ }^{22,24,36}$ two in Germany, ${ }^{18,38}$ and one each from Austria and Germany, ${ }^{23}$ Canada, ${ }^{37}$ Denmark, ${ }^{21}$ Netherlands, ${ }^{17}$ Spain ${ }^{19}$ and the UK. ${ }^{20}$ Participant recruitment into the trials occurred from 1992 to 2006, and trials were published between 2000 and 2010. The Coaguchek (Roche Diagnostics, Basel, Switzerland), Pro time microcoagulation (ITC Nexus Dx, Edison, NJ USA), and the Coumatrak monitor (Du Pont Pharmaceuticals, Wilmington, DE, USA) systems were used (table 1). For all trials, we verified clear methods for randomisation, allocation concealment, and intention-to-treat analyses. For publication bias, we saw no funnel-plot asymmetry and no bias with Begg's test: $\mathrm{p}=0 \cdot 35$ for thromboembolic events and $p=1.00$ for major haemorrhage; corresponding results of Egger's test were $p=0.05$ for thromboembolic events and $\mathrm{p}=0.92$ for major haemorrhage. 3266 (51\%) participants were randomly allocated to self-monitoring and 3151 to conventional care. Participants in the intervention group were on average 1.7 years $(64.2$ [SD 11.7] years vs 65.9 [SD 10.5] years; $p<0 \cdot 0001$ ) younger than those in the control groups. A wide range of ages was included: from 17 to 94 years of age, with 99 participants aged 85 years or older. 12800 person years of follow-up were obtained (mean 1.99 years [SD 1.22]), with a maximum follow-up of 1888 days $(5 \cdot 17$ years).

Over a third of participants had a mechanical heart valve insertion; one trial ${ }^{18}$ included only participants with this indication. Over half of participants had atrial fibrillation; one trial ${ }^{38}$ included only participants with this indication. For other disorders, over $10 \%$ of participants from nine trials ${ }^{17,19-24,36,37}$ were included. In eight trials,,$^{17-21,23,37,38}$ just under half (46\%) of those in the intervention group used self-management and in three trials, ${ }^{22,24,36}$ just over half (54\%) used self-testing only with dose adjustments undertaken by their regular clinician (table 1).

In four trials ${ }^{18,36-38}$ including a quarter of participants, primary care was used as the control and in another four trials ${ }^{17,19,22,24}$ including more than half $(61 \%)$ of participants, specialist anticoagulation clinics were used (table 1). In the three remaining trials, ${ }^{20,21,23}$ the control included either primary care or specialist clinics (table 1).

A significant reduction in thromboembolic events was seen in the self-monitoring group (hazard ratio 0.51 , $95 \%$ CI $0 \cdot 31-0 \cdot 85 ; \quad p=0 \cdot 010 ; \quad I^{2}=52 \cdot 6 \%$; figure 2 ). At 1 year, the number needed to treat to prevent one thromboembolic event was 78 (95\% CI 55-253), and by 5 years it was 27 (19-87; table 2). Individual study hazard ratios are shown in webappendix $\mathrm{p}$ 4. No significant reduction in major haemorrhagic events (hazard ratio $\left.0 \cdot 88,95 \% \mathrm{CI}, 0 \cdot 74-1 \cdot 06 ; \mathrm{p}=0 \cdot 18, I^{2}=0\right)$ or in deaths $\left(0 \cdot 82,0 \cdot 62-1 \cdot 09 ; \mathrm{p}=0 \cdot 18 ; I^{2}=37 \cdot 0\right)$ were apparent with self-monitoring (figure 2).

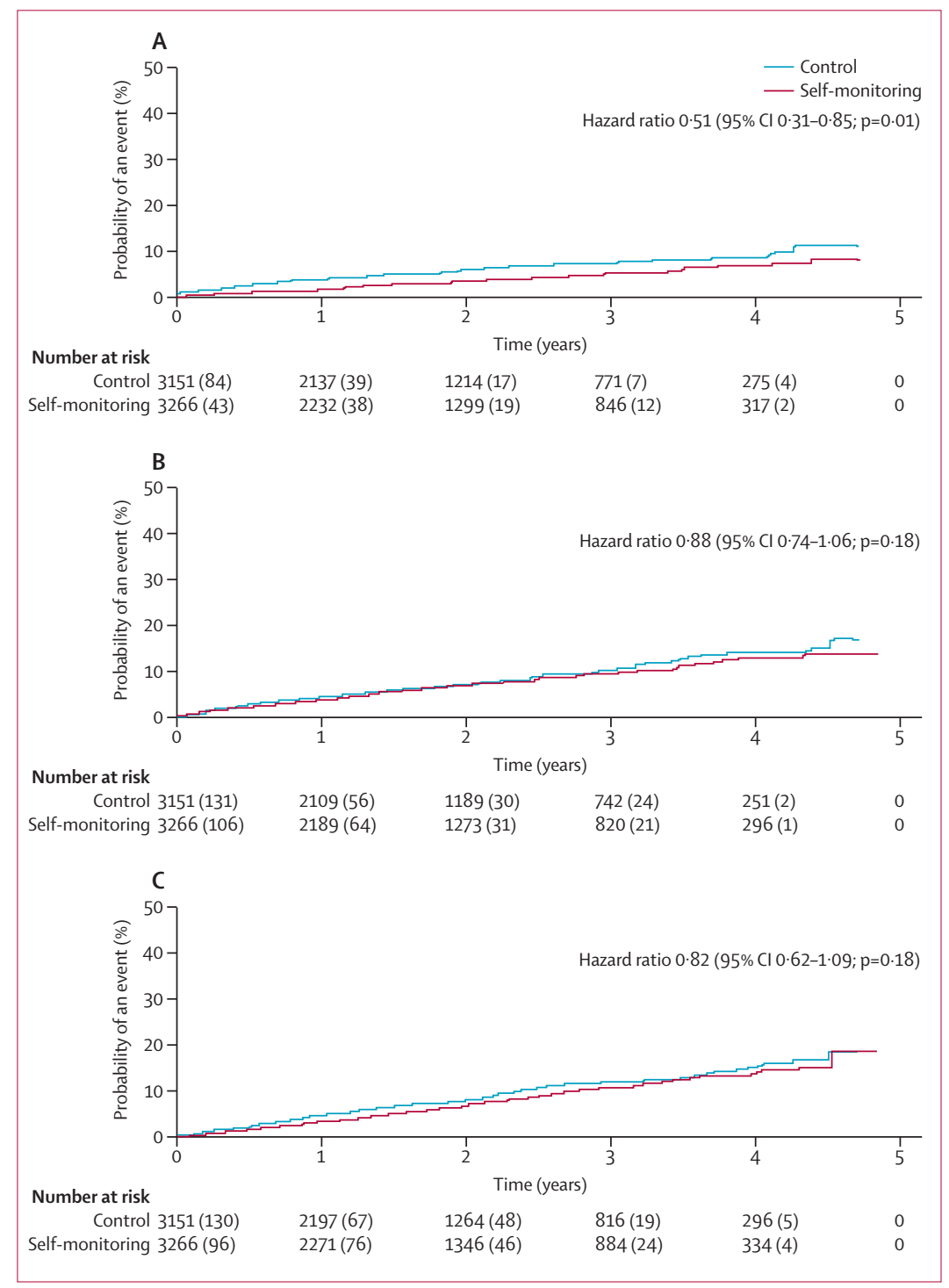

Figure 2: Hazard ratios for major outcomes

Hazard ratios for thrombotic events (152 events in the control group, 114 in the self-monitoring group; A), haemorrhagic events (244 in the control group, 230 in the self-monitoring group; B), and death (274 in the control group, 247 in the self-monitoring group; C) 


\begin{tabular}{|c|c|c|}
\hline & $\begin{array}{l}\text { Number needed } \\
\text { to treat }(95 \% \mathrm{Cl})\end{array}$ & $\begin{array}{l}\text { Number of patients } \\
\text { still at risk }\end{array}$ \\
\hline \multicolumn{3}{|c|}{ All participants ( $N=6417$ ) } \\
\hline \multicolumn{3}{|c|}{ Thrombosis } \\
\hline Year 1 & 78 (55 to 253 ) & 4369 \\
\hline Year 2 & 47 (33 to 154$)$ & 2513 \\
\hline Year 3 & 36 (26 to 119$)$ & 1617 \\
\hline Year 4 & 32 (23 to 104$)$ & 592 \\
\hline Year 5 & 27 (19 to 87$)$ & .. \\
\hline \multicolumn{3}{|c|}{ Major Haemorrhage } \\
\hline Year 1 & $205(94$ to $\infty)$ & 4598 \\
\hline Year 2 & $123(59$ to $\infty)$ & 2462 \\
\hline Year 3 & $96(44$ to $\infty)$ & 1564 \\
\hline Year 4 & $74(34$ to $\infty)$ & 547 \\
\hline Year 5 & 70 (32 to $\infty)$ & .. \\
\hline \multicolumn{3}{|l|}{ Death } \\
\hline Year 1 & $137(65$ to $\infty)$ & 4468 \\
\hline Year 2 & $82(39$ to $\infty)$ & 2610 \\
\hline Year 3 & 55 (26 to $\infty)$ & 1700 \\
\hline Year 4 & $47(22$ to $\infty)$ & 630 \\
\hline Year 5 & 42 (20 to $\infty)$ & .. \\
\hline \multicolumn{3}{|c|}{ Mechanical valve only ( $n=2243$ ) } \\
\hline \multicolumn{3}{|c|}{ Thrombosis } \\
\hline Year 1 & 55 (41 to 116 ) & 1721 \\
\hline Year 2 & 37 ( 28 to 78 ) & 589 \\
\hline Year 3 & $33(25$ to 70$)$ & 419 \\
\hline Year 4 & $31(23$ to 65$)$ & 186 \\
\hline Year 5 & 24 (18 to 50$)$ & 0 \\
\hline \multicolumn{3}{|c|}{ Major haemorrhage } \\
\hline Year 1 & $127(66$ to $\infty)$ & 1699 \\
\hline Year 2 & $65(34$ to $\infty)$ & 565 \\
\hline Year 3 & $43(22$ to $\infty)$ & 386 \\
\hline Year 4 & $31(16$ to $\infty)$ & 160 \\
\hline Year 5 & $29(15$ to $\infty)$ & .. \\
\hline \multicolumn{3}{|l|}{ Death } \\
\hline Year 1 & $156(67$ to $\infty)$ & 1763 \\
\hline Year 2 & $65(34$ to $\infty)$ & 618 \\
\hline Year 3 & $43(23$ to $\infty)$ & 442 \\
\hline Year 4 & $31(16$ to $\infty)$ & 202 \\
\hline Year 5 & $29(15$ to $\infty)$ & .. \\
\hline \multicolumn{3}{|c|}{ Atrial fibrillation only $(\mathrm{n}=3388)$} \\
\hline \multicolumn{3}{|c|}{ Thrombosis } \\
\hline Year 1 & $185(85$ to $\infty)$ & 2386 \\
\hline Year 2 & $91(42$ to $\infty)$ & 1860 \\
\hline Year 3 & $65(30$ to $\infty)$ & 1163 \\
\hline Year 4 & $54(25$ to $\infty)$ & 393 \\
\hline Year 5 & $49(23$ to $\infty)$ & .. \\
\hline \multicolumn{3}{|c|}{ Major haemorrhage } \\
\hline Year 1 & $675(79 \text { to } \infty)^{*}$ & 2344 \\
\hline Year 2 & $453(53 \text { to } \infty)^{*}$ & 1824 \\
\hline Year 3 & $342(40 \text { to } \infty)^{*}$ & 1134 \\
\hline Year 4 & $268(32 \text { to } \infty)^{*}$ & 373 \\
\hline \multirow[t]{2}{*}{ Year 5} & $255(30 \text { to } \infty)^{*}$ & $\cdot$ \\
\hline & & (Continues in next column \\
\hline
\end{tabular}

\begin{tabular}{|c|c|c|}
\hline & $\begin{array}{l}\text { Number needed to } \\
\text { treat }(95 \% \mathrm{Cl})\end{array}$ & $\begin{array}{l}\text { Number of patients } \\
\text { still at risk }\end{array}$ \\
\hline \multicolumn{3}{|c|}{ (Continued from previous column) } \\
\hline \multicolumn{3}{|l|}{ Death } \\
\hline Year 1 & $101(50$ to $\infty)$ & 2428 \\
\hline Year 2 & $56(28$ to $\infty)$ & 1921 \\
\hline Year 3 & $37(18$ to $\infty)$ & 1216 \\
\hline Year 4 & $30(15$ to $\infty)$ & 413 \\
\hline Year 5 & $26(13$ to $\infty)$ &.. \\
\hline \multicolumn{3}{|c|}{ The number needed to treat is estimated as: } \\
\hline Number needed to treat $=$ & $\frac{1}{\left(S c[t]^{h}-S c[t]\right)}$ & \\
\hline \multicolumn{3}{|l|}{ *Number needed to harm. } \\
\hline \multicolumn{3}{|c|}{$\begin{array}{l}\text { Table 2: Number needed to treat at various timepoints for all } \\
\text { self-monitoring participants with a mechanical valve and atrial } \\
\text { fibrillation compared with standard care }\end{array}$} \\
\hline
\end{tabular}

In prespecified subgroups the rate of thromboembolic events in men was significantly reduced in the selfmonitoring group (figure $3 ; \mathrm{p}=0 \cdot 010 ; I^{2}=61 \cdot 3$ ) whereas in women it was not (figure 3; $\mathrm{p}=0 \cdot 46 ; I^{2}=26 \cdot 6$;). However, the ratio of male to female participants was four to one (5012 men vs 1405 women) and the interaction test showed that these two subgroups did not differ significantly $\left(\chi^{2} 0 \cdot 01 ; p=0 \cdot 94\right)$. Participants younger than 55 years of age who self-monitored had a striking reduction in thromboembolic events (figure 3; $\mathrm{p}=0 \cdot 002$; $I^{2}=0$ ), whereas in other age groups non-significant effects were shown. In participants younger than 55 years, this result corresponded to a number needed to treat of 21 (95\% CI 17-42) to prevent one thromboembolic event at 1 year. Non-significant improvement in major outcomes was seen in the self-monitoring group with younger age $\left(\chi^{2} 7 \cdot 75 ; \mathrm{p}=0 \cdot 052\right)$.

In terms of indication, participants with a mechanical heart valve who self-monitored had significant reductions in thromboembolic events (figure $3 ; p=0 \cdot 001 ; I^{2}=0$ ). At 1 year the number needed to treat to prevent one event was 55 (95\% CI 41-116) and by 5 years it was 24 (18-50). Effects for both atrial fibrillation (figure $3 ; \mathrm{p}=0 \cdot 35$; $I^{2}=40 \cdot 9$ ) and other indications (figure $3 ; \mathrm{p}=0 \cdot 12 ; I^{2}=0$ ) were not significant. An interaction test $\left(\chi^{2} 6 \cdot 88\right.$, $\mathrm{p}=0 \cdot 032$ ) between indications was significant. Participants who self-managed oral anticoagulation also had significantly fewer thromboembolic events (figure 4; $\left.\mathrm{p}<0.001 ; I^{2}=0\right)$, whereas participants self-testing alone did not (figure 4; $\mathrm{p}=0 \cdot 51 ; I^{2}=50 \cdot 3$ ). The interaction test between self-testing and self-management for this difference was significant $\left(\chi^{2} 9 \cdot 81, p=0 \cdot 002\right)$. For participants self-managing, the number needed to treat to prevent one thromboembolic event was 39 (95\% CI 31-65). For major haemorrhage and death, we detected no significant effects or interactions by age, sex, indication, or type of monitoring (figure 3 ). 


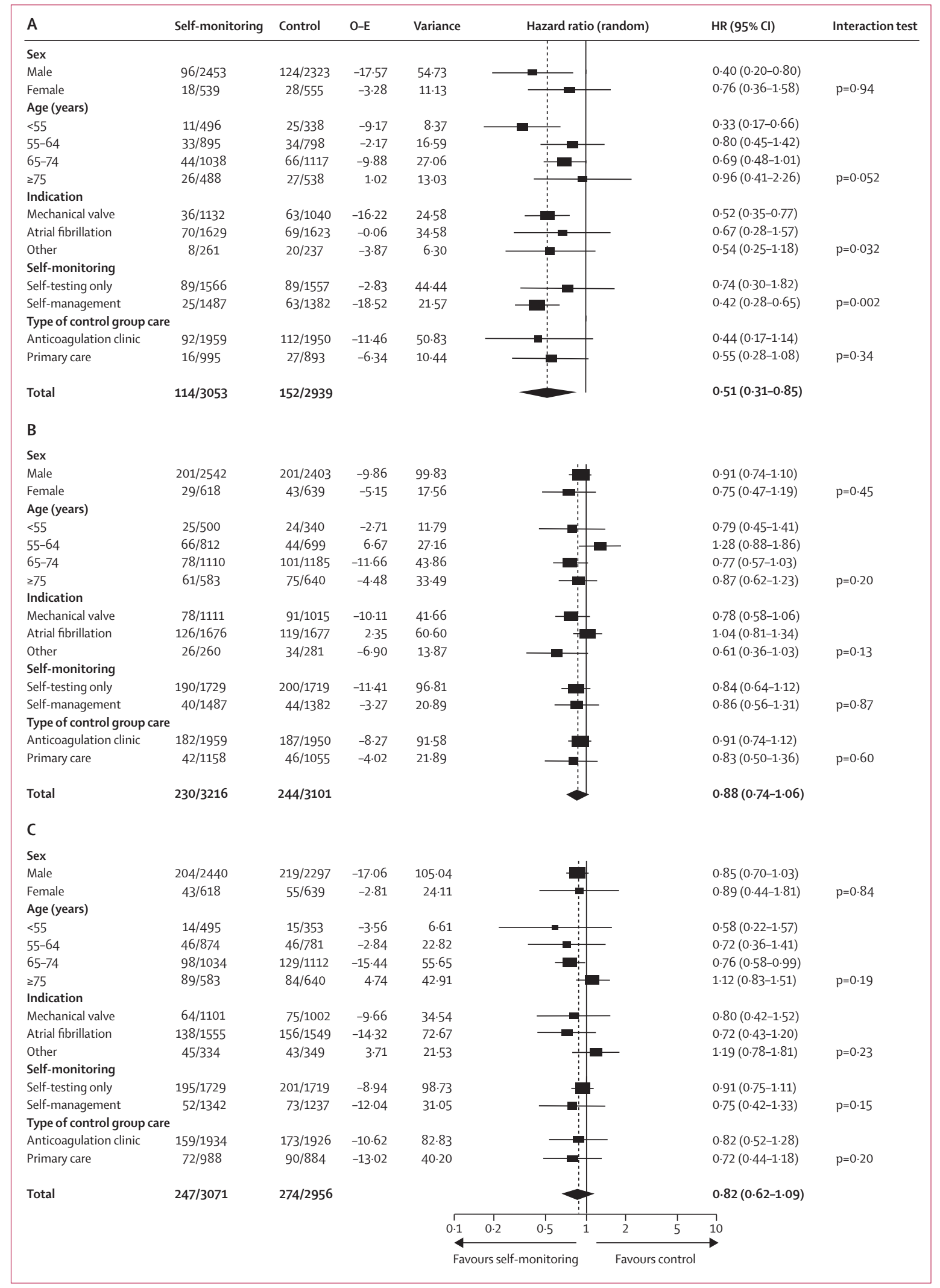

Figure 3: Major outcomes by sex, age, indication, type of monitoring and control group care

Thrombosis (A), major haemorrhage (B), and death (C). O-E=observed minus expected. 


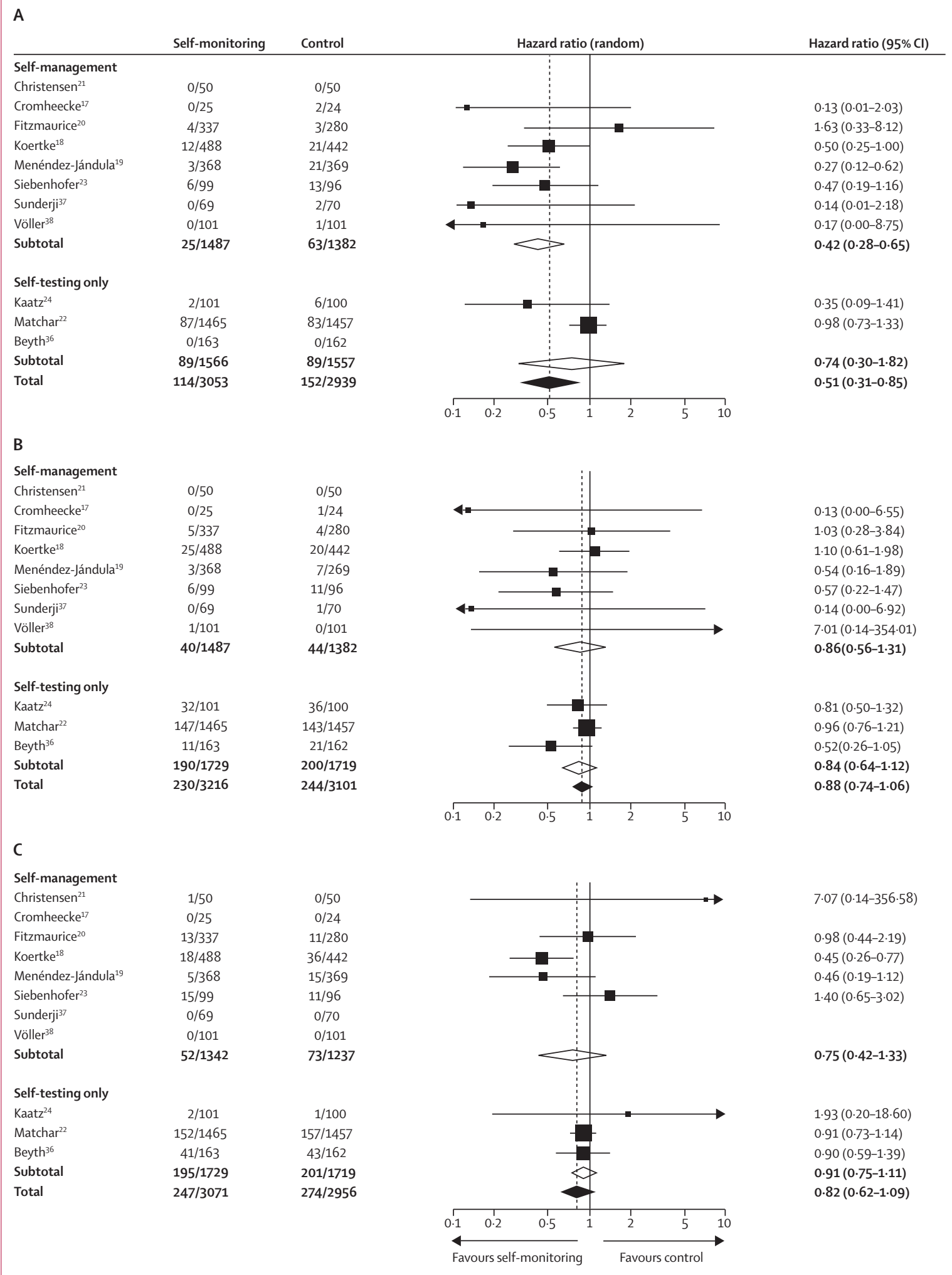

Figure 4: Comparison by type of monitoring (self-monitoring compared with self-testing only)

Thrombosis (A), major haemorrhage (B), and death (C). 


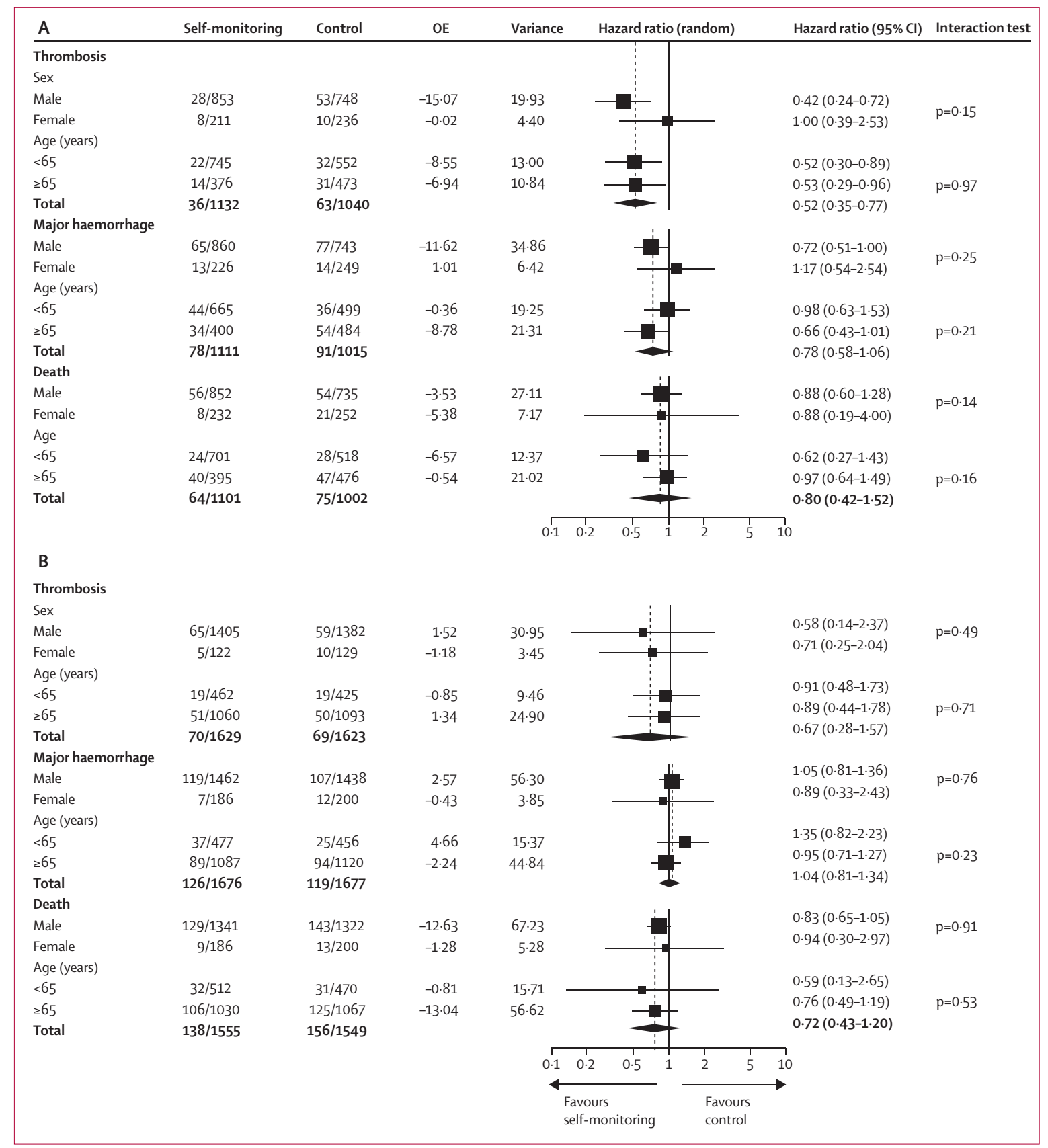

Figure 5: Major outcomes in mechanical valve and atrial fibrillation by age and sex

Patients with mechanical valve by sex and age ( $<65$ years and $\geq 65$ years; $A)$ and patients with atrial fibrillation by sex and age $(<65$ years and $\geq 65$ years; $B)$.

$\mathrm{O}-\mathrm{E}=$ observed minus expected.

Analysis of major outcomes in the very elderly $(\geq 85$ years, $n=99$ ) showed no significant adverse effects of self-monitoring for all outcomes, and a reduction in mortality was seen (hazard ratio $0 \cdot 44,95 \%$ CI $0 \cdot 20-0 \cdot 98$; $\mathrm{p}=0.044 ; I^{2}=0$ ); however, the number of participants in this analysis was small $(n=75)$.

We postulated that type of control care in our prespecified subgroups might affect the overall effectiveness of self-monitoring. Yet, little difference was seen in terms of anticoagulation clinic care versus primary care for thromboembolic events (figure $3 ; \chi^{2} 2 \cdot 18, \mathrm{p}=0 \cdot 34$ ); major haemorrhage $\left(\chi^{2} 1 \cdot 01, \mathrm{p}=0 \cdot 60\right)$, and death outcomes $\left(\chi^{2} 3 \cdot 25, p=0 \cdot 20\right)$.

A significant reduction in thromboembolic events was seen in men with a mechanical heart valve who were self-monitoring (figure $5 ; \mathrm{p}=0 \cdot 002, I^{2}=13 \cdot 8$ ), which was not significant in women (figure $5 ; \mathrm{p}=0 \cdot 99 ; I^{2}=5 \cdot 8$ ). However, the number of women was small $(n=447$ for 
thrombosis) and this interaction was not significant $\left(\chi^{2} 2 \cdot 04, p=0 \cdot 15\right)$. Men with a mechanical valve who were self-monitoring also had a significant reduction in major haemorrhagic events (figure $5 ; \mathrm{p}=0 \cdot 049 ; I^{2}=0$ ), whereas women did not (figure 5; $\mathrm{p}=0.69 ; I^{2}=0$ ). However, the interaction test was not significant $\left(\chi^{2} 1 \cdot 31, p=0 \cdot 25\right)$.

Participants younger than 65 years and those 65 years or older with a mechanical heart valve who were self-monitoring oral anticoagulation showed similar significant reductions with roughly a halving of thrombotic events (figure 5). We saw no significant effects or interaction in terms of major haemorrhage and death for other subgroups of participants with a mechanical valve. In participants with atrial fibrillation, we saw no significant effects across subgroups by sex or age, and no significant interactions (figure 5).

One study ${ }^{17}$ provided data only at 90 days for the mean time in therapeutic range (table 3 ). The time in therapeutic range improved and SDs decreased over time. By 1 year four trial $\mathrm{s}^{18,20-22}$ showed improvements in the intervention group, whereas the three trials, ${ }^{19,23,24}$ which did not show improvement, all had smaller SDs in the intervention group. In the first 7 days participants with atrial fibrillation and a mechanical heart valve who self-monitored oral anticoagulation spent significantly more time in therapeutic range than did those who did not self-monitor

\begin{tabular}{|c|c|c|c|c|c|c|c|c|c|c|c|}
\hline & \multirow[t]{2}{*}{ Country } & \multicolumn{2}{|l|}{7 days } & \multicolumn{2}{|l|}{30 days } & \multicolumn{2}{|l|}{90 days } & \multicolumn{2}{|l|}{6 months } & \multicolumn{2}{|l|}{1 year } \\
\hline & & Intervention & Control & Intervention & Control & Intervention & Control & Intervention & Control & Intervention & Control \\
\hline $\begin{array}{l}\text { Cromheecke } \\
\text { et } \mathrm{al}^{17}\end{array}$ & Holland & .. &.. &.. & .. & $57 \cdot 8(14 \cdot 5)$ & $47.8(18.6)$ & .. &.. & .. &.. \\
\hline Körtke et al ${ }^{18}$ & Germany & $49 \cdot 2 \%(42 \cdot 9)$ & $56 \cdot 9 \%(41 \cdot 3)$ & $71 \cdot 2 \%(28 \cdot 7)$ & $55 \cdot 7 \%(35 \cdot 5)$ & $78 \cdot 2 \%(22 \cdot 0)$ & $59.6 \%(32.5)$ & $80 \cdot 9 \%(20 \cdot 0)$ & $60 \cdot 6 \%(31 \cdot 2)$ & $83 \cdot 0 \%(18 \cdot 6)$ & $61 \cdot 7(30 \cdot 8)$ \\
\hline $\begin{array}{l}\text { Menéndez- } \\
\text { Jándula et al }\end{array}$ & Spain & $66 \cdot 7 \%(37 \cdot 4)$ & $62 \cdot 5 \%(44.7)$ & $66 \cdot 2 \%(26 \cdot 7)$ & $68 \cdot 2 \%(36 \cdot 2)$ & $66 \cdot 2 \%(18 \cdot 6)$ & $68 \cdot 5 \%(27 \cdot 2)$ & $68.0 \%(16.0)$ & $69 \cdot 0 \%(22 \cdot 3)$ & $67 \cdot 9 \%(14 \cdot 0)$ & $68.8(20.0)$ \\
\hline $\begin{array}{l}\text { Fitzmaurice } \\
{\text { et } \mathrm{a}^{20}}\end{array}$ & UK & $66 \cdot 6 \%(40 \cdot 4)$ & $53 \cdot 2 \%(45 \cdot 3)$ & $69 \cdot 7 \%(32 \cdot 2)$ & $63.9 \%(36.8)$ & $70 \cdot 7 \%(25 \cdot 1)$ & $63 \cdot 6 \%(31 \cdot 7)$ & $71.0 \%(23.0)$ & $63.4 \%(28.8)$ & $71 \cdot 7 \%(22 \cdot 0)$ & $63.8(28.4)$ \\
\hline $\begin{array}{l}\text { Christensen }{ }^{21} \\
\text { et al }\end{array}$ & Denmark & $80 \cdot 2 \%(24 \cdot 3)$ & $61 \cdot 7 \%(44 \cdot 1)$ & $78 \cdot 3 \%(24 \cdot 6)$ & $71 \cdot 2 \%(33 \cdot 7)$ & $77 \cdot 5 \%(20 \cdot 6)$ & $67.7 \%(30 \cdot 9)$ & $75 \cdot 5 \%(18.9)$ & $67 \cdot 3 \%(24 \cdot 5)$ & $75 \cdot 5 \%(18 \cdot 9)$ & $67 \cdot 4(24 \cdot 2)$ \\
\hline $\begin{array}{l}\text { Siebenhofer }{ }^{23} \\
\text { et al }\end{array}$ & Austria & $43 \cdot 6 \%(43 \cdot 5)$ & $52 \cdot 9 \%(44 \cdot 0)$ & $51 \cdot 0 \%(36 \cdot 6)$ & $61 \cdot 5 \%(35 \cdot 8)$ & $53 \cdot 6 \%(26 \cdot 2)$ & $63 \cdot 3 \%(29 \cdot 7)$ & $57 \cdot 4 \%(24 \cdot 5)$ & $65.0 \%(26 \cdot 5)$ & $61 \cdot 3 \%(19 \cdot 9)$ & $64 \cdot 5(21 \cdot 1)$ \\
\hline Matchar et al ${ }^{22}$ & USA & $63 \cdot 3 \%(21 \cdot 7)$ & $52 \cdot 3 \%(25 \cdot 1)$ & $63 \cdot 5 \%(16 \cdot 0)$ & $53 \cdot 0 \%(20 \cdot 3)$ & $64 \cdot 1 \%(14 \cdot 6)$ & $55 \cdot 1 \%(19 \cdot 9)$ & $65 \cdot 1 \%(14 \cdot 1)$ & $57 \cdot 7 \%(19 \cdot 9)$ & $67 \cdot 2 \%(14 \cdot 0)$ & $61 \cdot 0(20 \cdot 1)$ \\
\hline Kaatz et a $\left.\right|^{24}$ & USA & $59 \cdot 7 \%(40 \cdot 0)$ & $61 \cdot 1 \%(41 \cdot 6)$ & $56 \cdot 6 \%(28 \cdot 7)$ & $66.9 \%(32 \cdot 1)$ & $62 \cdot 9 \%(21 \cdot 6)$ & $70 \cdot 0 \%(25 \cdot 3)$ & $64.7 \%(19 \cdot 6)$ & $71 \cdot 6 \%(19 \cdot 9)$ & $65 \cdot 9 \%(17 \cdot 4)$ & $70 \cdot 8(17 \cdot 6)$ \\
\hline
\end{tabular}

\begin{tabular}{|c|c|c|c|c|c|c|}
\hline & \multicolumn{3}{|l|}{ Time in therapeutic range } & \multicolumn{3}{|l|}{ Number of tests } \\
\hline & $\begin{array}{l}\text { Mean difference between self-monitoring } \\
\text { and control group }(95 \% \mathrm{Cl})\end{array}$ & Heterogeneity & $\mathrm{p}$ value & $\begin{array}{l}\text { Mean difference between self-monitoring } \\
\text { and control group }(95 \% \mathrm{Cl})\end{array}$ & Heterogeneity & $p$ value \\
\hline 7 days & $12 \cdot 25 \%(8.99$ to $15 \cdot 51)$ & 0 & $<0.001$ & 0.25 (0.10 to 0.39$)$ & $77 \%$ & 0.001 \\
\hline 30 days & $6.13 \%(-0.09$ to 12.35$)$ & $72 \%$ & 0.05 & 2.28 (1.59 to 2.97$)$ & $94 \%$ & $<0.001$ \\
\hline 6 months & $5 \cdot 13 \%(-1 \cdot 13$ to $11 \cdot 40)$ & $79 \%$ & $0 \cdot 11$ & $12 \cdot 71$ ( $9 \cdot 33$ to $16 \cdot 10)$ & $96 \%$ & $<0.001$ \\
\hline 1 year & $2 \cdot 71 \%(-6 \cdot 10$ to $11 \cdot 51)$ & $94 \%$ & $0 \cdot 55$ & $24.22(18 \cdot 40$ to 30.04$)$ & $93 \%$ & $<0.001$ \\
\hline \multicolumn{7}{|c|}{ Data $\%$ or $\%(95 \% \mathrm{Cl})$. } \\
\hline
\end{tabular}

\begin{tabular}{|c|c|c|c|c|c|c|}
\hline & \multicolumn{3}{|l|}{ Time in therapeutic range } & \multicolumn{3}{|l|}{ Number of tests } \\
\hline & $\begin{array}{l}\text { Mean difference between self-monitoring } \\
\text { and control group }(95 \% \mathrm{Cl})\end{array}$ & Heterogeneity & $p$ value & $\begin{array}{l}\text { Mean difference between self-monitoring } \\
\text { and control group }(95 \% \mathrm{Cl})\end{array}$ & Heterogeneity & $p$ value \\
\hline 7 days & $10 \cdot 38 \%(8 \cdot 56$ to $12 \cdot 20)$ & $0 \%$ & $<0.001$ & $0.01(-0.25$ to 0.28$)$ & $92 \%$ & 0.91 \\
\hline 30 days & $3 \cdot 16 \%(-4 \cdot 07$ to $10 \cdot 39)$ & $77 \%$ & 0.39 & 1.78 (0.97 to 2.60$)$ & $97 \%$ & $<0.001$ \\
\hline 6 months & $4.40 \%(-0.86$ to 9.67$)$ & $79 \%$ & $0 \cdot 10$ & $12.03(7.46$ to $16 \cdot 60)$ & $99 \%$ & $<0.001$ \\
\hline 1 year & $5.13 \%(0.97$ to 9.28$)$ & $57 \%$ & 0.02 & $21 \cdot 74$ (13.11 to $30 \cdot 37)$ & $98 \%$ & $<0.001$ \\
\hline
\end{tabular}


(table 4, table 5), but over time the differences between groups reduced. Self-monitoring also led to an increase in the number of tests undertaken. At 1 year, participants with a mechanical valve or atrial fibrillation undertook more tests per year than did those receiving usual care (table 4, table 5). The substantial variation between studies was illustrated by the high heterogeneity.

\section{Discussion}

Our study used individual patient data for assessment of self-monitoring for oral anticoagulation. Overall, we observed a significant reduction in thromboembolic events in the self-monitoring group. However, we did not find any significant effects for major haemorrhage or mortality.

Our findings accord with those of previous systematic reviews, in which patients who self-monitor or selfmanage could improve the quality of their oralanticoagulation therapy. However, despite the decrease in the number of thromboembolic events without concomitant increases in harms, we did not see the reduction in mortality shown in previous systematic reviews. ${ }^{4-6}$ The odds ratio in a meta-analysis by Bloomfield and colleagues ${ }^{39}$ was similar to our result for reduction in thromboembolic events (odds ratio $0.58,95 \% \mathrm{CI}$ $0 \cdot 45-0 \cdot 75 ; \mathrm{p}<0 \cdot 001)$. However, the result for death was similar in effect size, but the observed result differed significantly (odds ratio $0.74,95 \%$ CI $0.63-0.87$; $\mathrm{p}<0 \cdot 001)$. This effect was highly heterogeneous $\left(I^{2}=51 \%\right)$, which was attributed to the largest study to date. ${ }^{22}$ Reasons given for this high heterogeneity were that this large study had substantially longer follow-up and higher quality of control in the usual care group than did other similar studies. The trend for reduction in mortality favoured self-monitoring, yet our previous estimate for a reliable and conclusive treatment effect would require 5150 participants in each study group. ${ }^{6}$ Potentially, unavailable data from the ten studies that we were unable to access, were sufficient to remove the significance of this result.

Additionally, our previous estimate that self-monitoring was feasible for only half of patients requiring anticoagulant therapy might underestimate the true numbers. In the largest trial,,$^{22}$ about $80 \%$ (2922 of 3643) of trained patients were competent in the use of selfmonitoring equipment. Yet, even this estimate is confounded by eligibility criteria: in several trials ${ }^{20,32}$ fewer than $50 \%$ of the potentially eligible patients were randomly assigned. Self-monitoring patients deemed not competent had higher numbers of practice attempts and higher cuvette wastage, and were less able to efficiently do a fingerstick procedure. ${ }^{40}$ Factors associated with unsuccessful self-monitoring include refusal by patients, exclusion by their family practitioner, failure to pass training, old age, poor cognition, and poor manual dexterity. ${ }^{6,20,40}$ One trial excluded people unable to attend training, ${ }^{19}$ and in another trial ${ }^{20}$ of an unselected population, young patients were more likely to successfully self-monitor oral anticoagulatoin.

In Germany $20 \%$ (160 000) of patients on anticoagulation undertook self-management, compared with only $1 \%$ of those in USA who did self-testing at home. Reasons for this difference include reimbursement, motivation by the patient, and willingness of the physician to support self-monitoring. ${ }^{20}$ Limitations include the reluctance of individuals to participate, but also the direct costs to patients and the training required for effective monitoring.

In patients younger than 55 years of age, two-thirds reduction in thromboembolic events translated into 21 participants self-monitoring for 1 year to prevent one thromboembolic event. For patients with a mechanical heart valve, a $50 \%$ decrease in thromboembolic events meant that the number needed to undertake selfmonitoring to prevent one event was 55 after 1 year and 24 over 5 years. By comparison, 63 patients are needed to prevent one heart attack with daily statin therapy over 5 years. ${ }^{41,42}$

Patients who self-tested and adjusted their doses had significantly lower rates of thromboembolic events, which suggests that patients should be given the opportunity, and provided with training, to undertake self-management. However, self-management does not mean that patients are left to fend for themselves: for instance, in one trial participants had $24 \mathrm{~h}$ back-up available, ${ }^{37}$ and good quality control measures are needed. The type of control care did not affect the overall effectiveness of self-monitoring. This finding is often contradictory to the evidence, which shows that patients from community practices have significantly worse anticoagulation control than do those from anticoagulation clinics. However, the same systematic review highlighted that patients recruited to clinical trials tended to spend more time in the therapeutic range than did those in the community. ${ }^{43}$

For participants with atrial fibrillation we reported no significant effects across subgroups by sex or age, and no significant interactions. Participants with atrial fibrillation were older than those with a mechanical heart valve, and in this age group, rates of events tended to be low. In a previous trial of 973 elderly patients in the community on anticoagulation, thromboembolic events were $1.4 \%$ a year. $^{44}$

Mean time in therapeutic range tended to be better in the self-monitoring groups. Importantly, even when the time in therapeutic range showed worse control, the SDs were less, which suggests lower variation and therefore more stable control of oral anticoagulation than in the control care group. ${ }^{45}$ Full analysis of this issue is beyond the scope of this report, but is an important issue in establishing optimum anticoagulation control.

We also reported a reduction in mortality in very elderly patients who self-monitored oral anticoagulation. This result, although potentially misleading owing to the small numbers and number of analyses, warrants further 
investigation. The evidence already supports the use of anticoagulation for elderly patients unless contraindications apply or patients decide the benefits are not worth the inconvenience of such treatment. ${ }^{44}$ Our review was restricted to adults, although increasing numbers of children receive warfarin. But self-monitoring could be a safe and effective management strategy for children and clinical studies are recommended. ${ }^{46}$

Some limitations are worth noting. First, we could have missed a study, especially because of non-publication. The results differ for publication bias because of variation in the methods for calculating Begg's and Egger's tests. Yet, the results of both suggest a weak effect of publication bias due to effects of small studies. Second, we were unable to obtain data from ten studies, although this was a small proportion of the overall dataset, which reduced the overall sample size. However, we were able to receive data from the largest trial to date, which was recently published. ${ }^{22}$ Third, some heterogeneity in outcomes was obsereved. Differences occurred in the populations (ie, the monitor and the intervention populations), which all add to the inherent variability. Fourth, only a small number of participants aged over 85 years were included, and further research in this age group is needed. Finally, we do not know why fewer women than men were included and whether this is because women are reluctant to participate in self-monitoring or the overall recruitment strategies target men. One reason could be that in the largest study, ${ }^{22}$ which comprised nearly half of the data, only $1.7 \%$ of the included participants were women. Furthermore, the study was done in a Veterans Affairs population, which mainly includes men.

Adoption of self-monitoring will depend on findings from economic analyses, which in the past have produced conflicting results. In the UK, a review concluded "in general, patient self-management is unlikely to be more cost-effective than the current specialised anticoagulation clinics," ${ }^{47}$ whereas a Canadian study suggested: "selfmanagement is a cost-effective strategy for patients receiving long-term oral anticoagulation therapy for atrial fibrillation or for a mechanical heart valve". ${ }^{48}$

We believe the results of our review will lead to a systematic change in practice, in terms of the significant reduction in thromboembolic events in patients with a mechanical heart valve requiring long-term anticoagulation. Such patients should be offered the option to self-manage their disease with suitable health-care support as back-up. Additionally, several reviews and our study show that self-monitoring and self-management is a safe option for suitable patients. ${ }^{5,6,49}$

\section{Contributors}

Members named in the writing committee contributed to the data collection or the systematic review and data analysis, and to the preparation of the published Article.

Collaborators

Writing committee Carl Heneghan, Alison Ward, Rafael Perera, Clare Bankhead, Alice Fuller, Richard Stevens, Kairen Bradford,
Sally Tyndel (Oxford University, Oxford, UK), Pablo Alonso-Coello (Institute of Biomedical Research [IIB Sant Pau], Barcelona, Spain), Jack Ansell (Lenox Hill Hospital, New York, USA), Rebecca Beyth (University of Florida, FL, USA), Artur Bernardo (Klinik Gais AG, Gais Switzerland), Thomas Decker Christensen (Aarhus University Hospital, Skejby, Aarhus, Denmark), M E Cromheecke (Academic Medical Centre, University of Amsterdam, Netherlands), Robert G Edson (VA Cooperative Studies Program Coordinating Center, Palo Alto, CA, USA),

David Fitzmaurice (University of Birmingham, Birmingham, UK), Alain P A Gadisseur (Antwerp University Hospital, Antwerp, Belgium), Josep M Garcia-Alamino (Oxford University, Oxford, UK), Chris Gardiner (University of Oxford, Oxford, UK), J Michael Hasenkam (Aarhus University Hospital, Skejby, Aarhus, Denmark), Alan Jacobson (Loma Linda University, CA, USA), Scott Kaatz (Henry Ford Hospital, Detroit, USA), Farhad Kamali (Newcastle University, Newcastle upon Tyne, UK), Tayyaba Irfan Khan (Newcastle University, Newcastle upon Tyne, UK), Eve Knight (Anticoagulation Europe, Kent, UK), Heinrich Körtke (Institute of Applied Telemedicine, Bad Oeynhausen, Germany), Marcel Levi (Academic Medical Centre, University of Amsterdam, The Netherlands), David Matchar (Duke Center of Clinical Health Policy Research, Durham, NC, USA), Bárbara Menéndez-Jándula (Hospital de la Santa Creu i Sant Pau, Barcelona, Spain), Ivo Rakovac (Institute for Biomedicine and Health Sciences, Graz, Austria), Christian Schaefer (International Self-Monitoring Association of Oral Anticoagulation Patients [ISMAAP], Geneva, Switzerland), Andrea Siebenhofer (Goethe University, Frankfurt, Germany), Juan Carlos Souto (Hospital de la Santa Creu i Sant Pau, Barcelona, Spain), Rubina Sunderji (University of British Columbia and Vancouver General Hospital, Vancouver, Canada), Kenneth Gin (University of British Columbia and Vancouver General Hospital, Vancouver, Canada), Karen Shalansky (University of British Columbia and Vancouver General Hospital, Vancouver, Canada), Heinz Völler (Center of Rehabilitation Research, Potsdam University, Potsdam, Germany), Otto Wagner (Ruhr Universität Bochum, Bad Oeynhausen, Germany), Armin Zittermann (Ruhr Universität Bochum, Bad Oeynhausen, Germany). Analysis committee Rafael Perera, Clare Bankhead, Richard Stevens, Carl Heneghan, Alison Ward, Alice Fuller. Data management committee Alison Ward, Alice Fuller, Rafael Perera, Clare Bankhead, Richard Stevens. Original trialists Rebecca Beyth, Thomas Decker Christensen, M E Cromheecke, Robert G Edson, David Fitzmaurice, Alain P A Gadisseur, Chris Gardiner J Michael Hasenkam, Alan Jacobson, Scott Kaatz, Farhad Kamali, Tayyaba Irfan Khan, Heinrich Körtke, Marcel Levi, David Matchar, Bárbara Menéndez-Jándula, Ivo Rakovac, Andrea Siebenhofer, Juan Carlos Souto, Rubina Sunderji, Kenneth Gin, Karen Shalansky, Heinz Völler, Otto Wagner, Armin Zittermann.

\section{Conflicts of interest}

Department of Primary Health Care, Oxford University (UK) received funding from the National Institute for Health Research Technology Assessment Programme (NIHR HTA; UK) and NIHR National School for Primary Care Research (UK); Iberoamerican Cochrane Centre received funding from Instituto de Salud Carlos III; Jack Ansell received funding from Alere ITC; Rebecca Beyth received funding from the 5th International Patient/Physician Conference on Oral Anticoagulant Therapy and the NIHR, University of Florida, Department of Veterans Affairs, and US National Institutes of Health; Robert Edson received funding from VA Cooperative Studies Program; Alain P A Gadisseur received funding from Roche Diagnostics, Bayer Healthcare and Boehringer Ingelheim; Department of Haemotology, Antwerp University Hospital (Germany) received funding from Bayer Healthcare; University College London Hospital (UK) received funding from Roche Diagnostics; J Michael Hasenkam received funding from Roche Diagnostics, Johnson \& Johnson, Edwards Lifesciences, and Nycomed; Department of Cardiothoracic Surgery, Aarhus University Hospital (Denmark) received funding from National Board of Health; Alan Jacobson received funding from Anticoagulation Forum, Loma Linda Veterans Association for Research, Biosite Corporation, Boehringer Ingelheim, Daiichi Sankyo, Farallon Medical, Hemosene, Inverness Medical, Pfizer Medical, Quality Assured Services, Roche Diagnostics, Sanofi-Aventis, Tapestry Medical, GlaxoSmithKline, and VA Cooperative Studies Program and was the co-chair of the THINRS 
study; Department of Internal Medicine, Loma Linda University (USA) received funding from Loma Linda Veterans Association for Research, Biosite Corporation, Boehringer Ingelheim, Farallon Medical, Hemosene, Inverness Medical, and Sanofi-Aventis; Scott Kaatz received funding from Biosite and Vox media; Department of Internal Medicine, Henry Ford Hospital (USA) received funding from Roche Diagnostics; Institute of Cellular Medicine, University of Newcastle (UK) received funding from Heart Research UK; Wolfson Unit of Clinical Pharmacology, School of Clinical and Laboratory Sciences, University of Newcastle (UK) received funding from the BUPA Foundation and Coaguchek; Anticoagulation Europe received funding from Roche Diagnostics; David Matchar received funding from Boerhinger Ingelheim, Roche, and VA Cooperative Studies Program and was the Co-Chair of the THINRS study; Juan Carlos Souto is the Scientific Director of Monitor Medical.

\section{References}

1 Fitzmaurice DA, Gardiner C, Kitchen S, Mackie I, Murray ET, Machin SJ. An evidence-based review and guidelines for patient self-testing and management of oral anticoagulation. Br J Haematol 2005; 131: 156-165.

2 Szucs TD, Bramkamp M. Pharmacoeconomics of anticoagulation therapy for stroke prevention in atrial fibrillation: a review. J Thromb Haemost 2006; 4: 1180-85.

3 Poller L, Keown M, Chauhan N, et al. European concerted action on anticoagulation. Quality assessment of the CoaguChek Mini and TAS PT-NC point-of-care whole-blood prothrombin time monitors. Clin Chem 2004; 50: 537-44.

4 Christensen TD, Johnsen SP, Hjortdal VE, Hasenkam JM. Self-management of oral anticoagulant therapy: a systematic review and meta-analysis. Int J Cardiol 2007; 118: 54-61.

5 Heneghan C, Alonso-Coello P, Garcia-Alamino JM, Perera R, Meats E, Glasziou P. Self-monitoring of oral anticoagulation: a systematic review and meta-analysis. Lancet 2006; 367: 404-11.

6 Garcia-Alamino JM, Ward AM, Alonso-Coello P, et al. Self-monitoring and self-management of oral anticoagulation. Cochrane Database Syst Rev 2010; 4: CD003839.

7 Ansell J, Jacobson A, Levy J, Voller H, Hasenkam JM. Guidelines for implementation of patient self-testing and patient self-management of oral anticoagulation. International consensus guidelines prepared by International Self-Monitoring Association for Oral Anticoagulation. Int J Cardiol 2005; 99: 37-45.

8 Lip GY, Rudolf M, Kakar P. Management of atrial fibrillation: the NICE guidelines. Int J Clin Pract 2007; 61: 9-11.

9 Perera R, Heneghan C, Fitzmaurice D. Individual patient meta-analysis of self-monitoring of an oral anticoagulation protocol. J Heart Valve Dis 2008; 17: 233-38.

10 Dickersin K, Manheimer E, Wieland S, Robinson KA, Lefebvre C, McDonald S. Development of the Cochrane Collaboration's CENTRAL Register of controlled clinical trials. Eval Health Prof 2002; 25: 38-64.

11 Schulman S, Kearon C. Definition of major bleeding in clinical investigations of antihemostatic medicinal products in non-surgical patients. J Thromb Haemost 2005; 3: 692-94.

12 Tinazzi A, Tierney J, Stewart L, Parmar M, Torri V. Survival curve and hazard ratio program (SCHARP) for meta-analysis of individual patient data.

Syst Rev Evid Action Int Cochrane Colloq 6th 1998 Baltim Md 1998; 6: 65 .

13 Tierney JF, Stewart LA, Ghersi D, Burdett S, Sydes MR. Practical methods for incorporating summary time-to-event data into meta-analysis. Trials 2007; 8: 16.

14 DerSimonian R, Laird N. Meta-analysis in clinical trials. Control Clin Trials 1986; 7: 177-88.

15 Higgins JP, Thompson SG, Deeks JJ, Altman DG. Measuring inconsistency in meta-analyses. BMJ 2003; 327: 557-60.

16 Altman DG, Andersen PK. Calculating the number needed to treat for trials where the outcome is time to an event. BMJ 1999; 319: 1492-95.

17 Cromheecke ME, Levi M, Colly LP, et al. Oral anticoagulation self-management and management by a specialist anticoagulation clinic: a randomised cross-over comparison. Lancet 2000; 356: 97-102.
18 Körtke H, Minami K, Breymann T, et al. INR self-management after mechanical heart valve replacement: ESCAT (Early Self-Controlled Anticoagulation Trial). Z Kardiol 2001; 90 (suppl 6): 118-24.

19 Menendez-Jandula B, Souto JC, Oliver A, et al. Comparing self-management of oral anticoagulant therapy with clinic management: a randomized trial. Ann Intern Med 2005; 142: 1-10.

20 Fitzmaurice DA, Murray ET, McCahon D, et al. Self management of oral anticoagulation: randomised trial. BMJ 2005; 331: 1057.

21 Christensen TD, Maegaard M, Sorensen HT, Hjortdal VE, Hasenkam JM. Self-management versus conventional management of oral anticoagulant therapy: a randomized, controlled trial. Eur J Intern Med 2006; 17: 260-66.

22 Matchar DB, Jacobson A, Dolor R, et al. Effect of home testing of international normalized ratio on clinical events. $N$ Engl J Med 2010; 363: 1608-20.

23 Siebenhofer A, Rakovac I, Kleespies C, Piso B, Didjurgeit U. Self-management of oral anticoagulation reduces major outcomes in the elderly. A randomized controlled trial. Thromb Haemost 2008; 100: 1089-98.

24 Kaatz S, Elston-Lafata J, Gooldy S. Anticoagulation therapy home and office monitoring evaluation study. J Thromb Thrombolysis 2001; 12: 111.

25 Rosendaal FR, Cannegieter SC, van der Meer FJ, Briet E. A method to determine the optimal intensity of oral anticoagulant therapy. Thromb Haemost 1993; 69: 236-39.

26 White RH, McCurdy SA, von Marensdorff H, Woodruff DE Jr, Leftgoff L. Home prothrombin time monitoring after the initiation of warfarin therapy. A randomized, prospective study. Ann Intern Med 1989; 111: 730-37.

27 Horstkotte D, Piper C, Wiemer M. Optimal frequency of patient monitoring and intensity of oral anticoagulation therapy in valvular heart disease. J Thromb Thrombolysis 1998; 5 (suppl 1): 19-24.

28 Sawicki PT. A structured teaching and self-management program for patients receiving oral anticoagulation: a randomized controlled trial. Working group for the study of patient self-management of oral anticoagulation. JAMA 1999; 281: 145-50.

29 Khan TI, Kamali F, Kesteven P, Avery P, Wynne H. The value of education and self-monitoring in the management of warfarin therapy in older patients with unstable control of anticoagulation. Br J Haematol 2004; 126: 557-64.

30 Fitzmaurice DA, Murray ET, Gee KM, Allan TF, Hobbs FD A randomised controlled trial of patient self management of oral anticoagulation treatment compared with primary care management. J Clin Pathol 2002; 55: 845-49.

31 Sidhu P, O'Kane HO. Self-managed anticoagulation: results from a two-year prospective randomized trial with heart valve patients. Ann Thorac Surg 2001; 72: 1523-27.

32 Gadisseur AP, Breukink-Engbers WG, van der Meer FJ, van den Besselaar AM, Sturk A, Rosendaal FR. Comparison of the quality of oral anticoagulant therapy through patient self-management and management by specialized anticoagulation clinics in the Netherlands: a randomized clinical trial. Arch Intern Med 2003; 163: 2639-46.

33 Gardiner C, Williams K, Longair I, Mackie IJ, Machin SJ, Cohen H. A randomised control trial of patient self-management of oral anticoagulation compared with patient self-testing. $\mathrm{Br} J$ Haematol 2006; 132: 598-603.

34 Dauphin C, Legault B, Jaffeux P, et al. Comparison of INR stability between self-monitoring and standard laboratory method: preliminary results of a prospective study in 67 mechanical heart valve patients. Arch Cardiovasc Dis 2008; 101: 753-61.

35 Soliman Hamad MA, van Eekelen E, van Agt T, van Straten AH. Self-management program improves anticoagulation control and quality of life: a prospective randomized study. Eur J Cardiothorac Surg 2009; 35: 265-69.

36 Beyth RJ, Quinn L, Landefeld CS. A multicomponent intervention to prevent major bleeding complications in older patients receiving warfarin. A randomized, controlled trial. Ann Intern Med 2000; 133: 687-95.

37 Sunderji R, Gin K, Shalansky K, et al. A randomized trial of patient self-managed versus physician-managed oral anticoagulation. Can J Cardiol 2004; 20: 1117-23. 
38 Völler H, Glatz J, Taborski U, Bernardo A, Dovifat C, Heidinger K. Self-management of oral anticoagulation in nonvalvular atrial fibrillation (SMAAF study). Z Kardiol 2005; 94: 182-86.

39 Bloomfield HE, Krause A, Greer N, et al. Meta-analysis: effect of patient self-testing and self-management of long-term anticoagulation on major clinical outcomes. Ann Intern Med 2011; 154: 472-82.

40 Dolor RJ, Ruybalid RL, Uyeda L, et al. An evaluation of patient self-testing competency of prothrombin time for managing anticoagulation: pre-randomization results of VA Cooperative Study \#481-The Home INR Study (THINRS). J Thromb Thrombolysis 2010; 30: 263-75.

41 Baigent C, Keech A, Kearney PM, et al. Efficacy and safety of cholesterol-lowering treatment: prospective meta-analysis of data from 90,056 participants in 14 randomised trials of statins. Lancet 2005; 366: 1267-78.

42 Thavendiranathan P, Bagai A, Brookhart MA, Choudhry NK. Primary prevention of cardiovascular diseases with statin therapy: a meta-analysis of randomized controlled trials. Arch Intern Med 2006; 166: 2307-13.

43 van Walraven C, Jennings A, Oake N, Fergusson D, Forster AJ. Effect of study setting on anticoagulation control: a systematic review and metaregression. Chest 2006; 129: 1155-66.
44 Mant J, Hobbs FD, Fletcher K, et al. Warfarin versus aspirin for stroke prevention in an elderly community population with atrial fibrillation (the Birmingham Atrial Fibrillation Treatment of the Aged Study, BAFTA): a randomised controlled trial. Lancet 2007; 370: 493-503.

45 Glasziou PP, Irwig L, Heritier S, Simes RJ. Monitoring cholesterol levels: measurement error or true change? Ann Intern Med 2008; 148: 656-61.

46 Bauman ME, Black K, Bauman ML, et al. EMPoWarMENT: Edmonton pediatric warfarin self-management pilot study in children with primarily cardiac disease. Thromb Res 2010; 126: e110-15.

47 Connock M, Stevens C, Fry-Smith A, et al. Clinical effectiveness and cost-effectiveness of different models of managing long-term oral anticoagulation therapy: a systematic review and economic modelling. Health Technol Assess 2007; 11: iii-66.

48 Regier DA, Sunderji R, Lynd LD, Gin K, Marra CA. Cost-effectiveness of self-managed versus physician-managed oral anticoagulation therapy. CMAJ 2006; 174: 1847-52.

49 Siebenhofer A, Berghold A, Sawicki PT. Systematic review of studies of self-management of oral anticoagulation. Thromb Haemost 2004; 91: 225-32. 